\title{
The Seasonal Differences in the Hydrology of the Kaliningrad Region's Coastal Waters
}

\author{
Viktor A. Krechik
}

Maria V. Kapustina

Ekaterina S. Bubnova

\author{
Vladimir A. Gritsenko* \\ Immanuel Kant Baltic Federal University, Russian Federation \\ *Corresponding Email: VGritsenko@kantiana.ru
}

\section{Doi:10.5901/mjss.2015.v6n6s7p90}

\begin{abstract}
Based on the instrumental measurements carried out in the period from 2003 to 2014 to isobath $3 \mathrm{~m}$ in the Kaliningrad region's coastal waters, the seasonal mean vertical profiles of temperature and salinity fields are received. Temporal and spatial differences in the distribution of basic hydrological parameters are identified.
\end{abstract}

Keywords: Kaliningrad region, coastal waters, sustainable development, landscape planning

\section{Introduction}

Despite the fact that the Baltic Sea is relatively well studied (Dubravin \& Stont, 2012; Atlas ..., 1994), the coastal waters of the Baltic Sea washing the shores of the Kaliningrad region are not fully described. With the existing climate data (ESIMO Atlas) it is not possible to see details of the seasonal hydrology variability of the coastal waters. In international public databases (HELCOM, ICES) the Russian sector of the south-eastern Baltic is poorly represented.

The paper is aimed at describing the seasonal differences of vertical thermohaline structure of the waters of the south-eastern part of the Baltic Sea off the Kaliningrad region's coast.

\section{Data Array}

The work is based on the instrumental measurement outputs at 1,862 stations obtained from vessels, motor boats and yachts from 2003 to 2014 by the staff of the I. Kant Baltic Federal University, M. Lomonosov Moscow State University and the P.P. Shirshov Atlantic Branch of the Institute of Oceanology of the RAS in the territorial waters of the Kaliningrad region. The general arrangement of stations is shown in Figure 1. Due to the shallow draft of motor boats and yachts it was possible to take measurement starting at $3 \mathrm{~m}$ isobath.

To assess the influence of the geomorphological factor on the hydrology of the coastal waters, the total measurement volume was divided into four subregions (see. Figure 1). Those are the waters near the Cape Taran, the North Shore and Sambia-Curonian hills and near-shore zone waters of the northern coast (Coastal Zone subregion). The external maritime boundary for all the subregions except the Coastal Zone subregionwas drawn along the $50 \mathrm{~m}$ isobath due to the winter convection penetration depth up to 50-60 m in the Gdansk Basin (Dubravin \& Stont, 2012). The external boundary of the coastal zone is considered to be a depth equal to half the wavelength of the largest storm waves (Leontiev, 2001). In the Gdansk Basin it passes near the $30 \mathrm{~m}$ isobath (Babakov, 2003). In this paper, the external boundary of the coastal zone is marked along the $20 \mathrm{~m}$ isobath. The boundaries of the seasons compared with the climatic divides were chosen with the chronological shift for one month upward, the months of January and March are taken in winter; correspondingly, spring is from April to June, summer is July-September, autumn is October-December (Dubravin \& Stont, 2012).

To construct the average seasonal hydrological parameters distribution profiles by depth in all subregions, their median values for each one-meter layer from the surface to the bottom were calculated (Piterbarg \& Gritsenko, 1983; Belkin 1991).

The climatic data for comparison were taken from the World Ocean Atlas 2013 made according to measurements 
from 1955 to 2012 (World Ocean Atlas, 2013). Some points from the Atlas (Figure 1) were selected on the basis of proximity to the selected subregions.

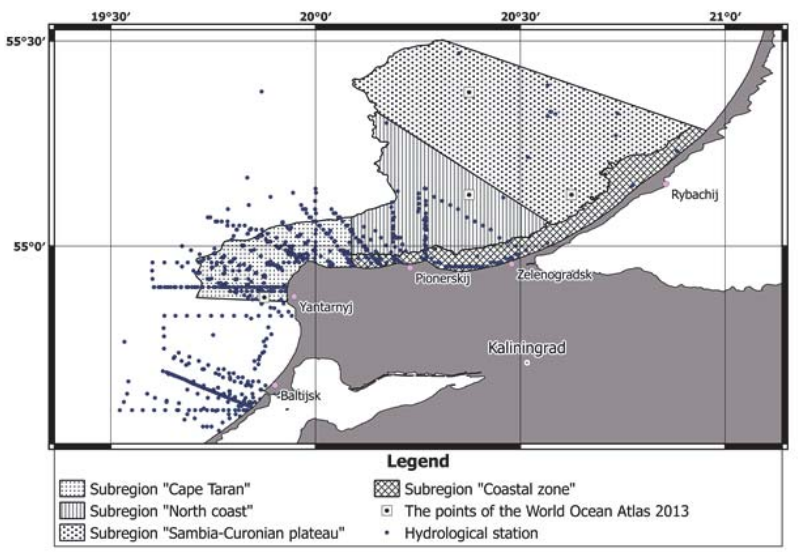

Figure 1. The map of datastation distribution.

Salinity. A relatively small variability of salinity in the seasonal and special terms is common for all subregions. The entire range of variability of salinity of the coastal waters fits into $1-1.5 \mathrm{psu}$ (see Figure 2).

In winter, the vertical structure of salinity field of all the subregions can be characterised by the presence of two quasi-homogeneous layers with a small gradient layer separating them, which corresponds to the climatic concepts. The values of salinity, thickness and depth of occurrence are slightly different for each of the subregions (Fig. 2a).
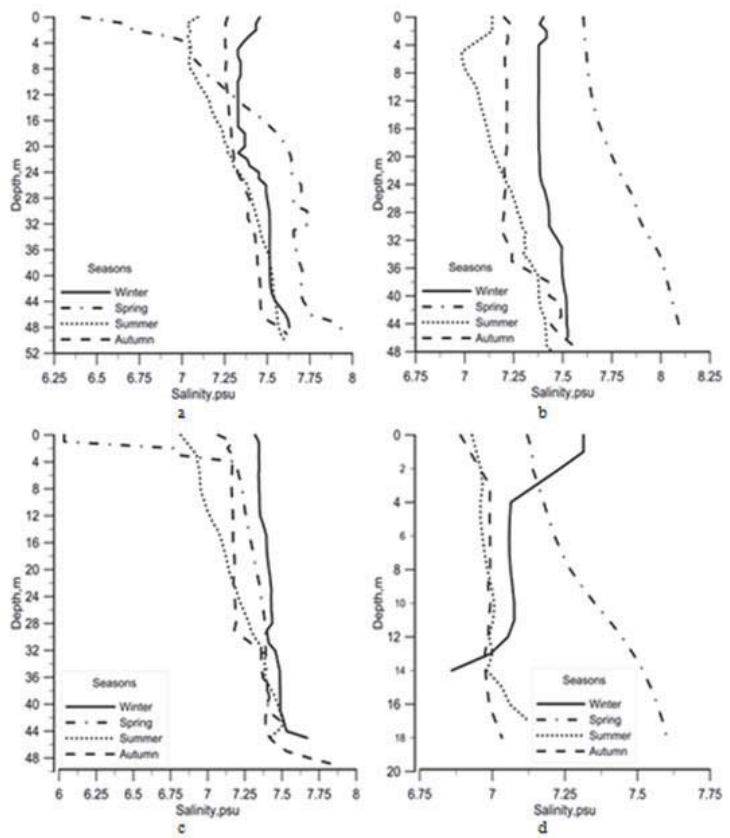

Note: a - Subregion Cape Taran; b - Subregion North coast; c - Subregion Sambia-Curonian plateau; d - Subregion Coastal zone.

Figure 2. Profiles of the median values of salinity for seasons. 
On the surface of the entire coastal zone there is a layer of high salinity water layer with the capacity of up to $2 \mathrm{~m}$, the origin of which seems to be related to ice formation. At the profile bottom from the depth of $11 \mathrm{~m}$, salinity values decrease reaching $6.67 \mathrm{psu}$ at the bottom (Figure $2 \mathrm{~d}$ ).

The vertical distribution of salinity in spring is characterised by the appearance on the surface of subregion Cape Taran and Sambia-Curonian hills of the freshened layer with a capacity of up to $2 \mathrm{~m}$ and a smooth increase in salinity values with the depth of up to 7.5-7.7 psu (Figure 2a, d). In two other regions there are rather high values reaching in the North Coast subregion 8 psu in the bottom layer (Figure 2b).

The salinity profile in summer is characterised by the variability in the upper part to a depth of 6-8 $\mathrm{m}$, and at deeper levels, salinity uniformly increases to 7.5 psu at the bottom (Figure 2).

The vertical distribution of water salinity in autumn is quasihomogeneous to the depths of 25-35 metres (about 7.3 psu). In the Coastal Zone in autumn the profile has a freshened surface layer the salinity which is 6.89 psu (Figure 2d). Only in the subregion Sambia-Curonian hills the vertical distribution of salinity in in autumn is determined by two quasihomogeneous layers (Figure 2c) with the water salinity of 7.18 and 7.37 psu respectively.

Temperature. The vertical structure of the temperature field of coastal waters generally quite corresponds to the climate data.

In winter, the water layer of coastal waters at that time is typical of inverse thermal stratification with a gradual increase in temperature within the depth range of 2-30 m. Below and to the bottom there is a weakly-gradient layer with a temperature at the bottom of $3.8^{\circ} \mathrm{C}$. The mean seasonal temperature of the surface layer is $2^{\circ} \mathrm{C}$ (Figure 3 ).
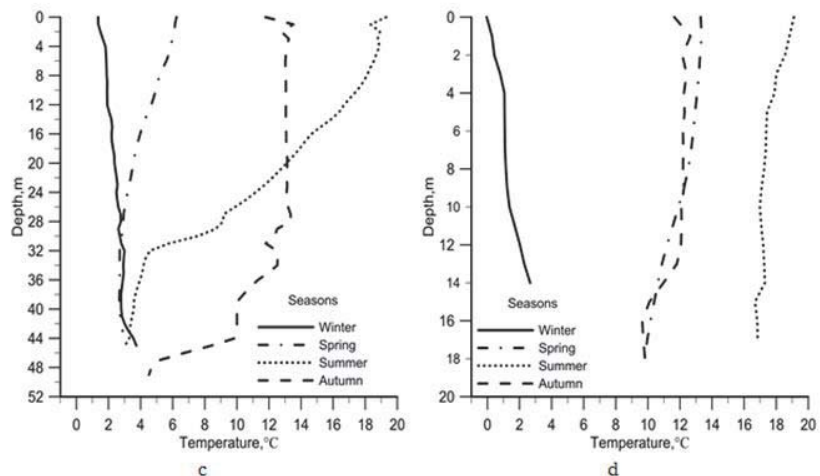

Note: a - Subregion Cape Taran; b - Subregion North coast; c - Subregion Sambia-Curonian plateau; d - Subregion Coastal zone.

Figure 3. Profiles of the median values of temperature for seasons.

In the shallowest Coastal Zone the water layer with the inverse thermal stratification is within the entire range of depths and has an average temperature of $1.3^{\circ} \mathrm{C}$. It is a consequence of the vertical convection and wind and wave mixing (Figure 3d).

With the onset of water warm-up in spring there will be an increase in temperature, and there is a return to the direct thermal stratification in all subregions (Figure 3).

At Cape Taran, the seasonal temperature for the surface quasihomogeneous layer with the thickness of up to $8 \mathrm{~m}$ is $14.5^{\circ} \mathrm{C}$. At deeper levels there is a smooth temperature drop to $3.3^{\circ} \mathrm{C}$ at the bottom (Figure $3 \mathrm{a}$ ). In the subregions North Coast and Sambia-Curonian hills the warm temperature values in spring slowly fall from the surface to the depths of 30-32 $\mathrm{m}$ where the temperature distribution pattern becomes homogeneous (Figure $3 b, c)$.

In the Coastal Zone spring warming significantly increases the temperature of the entire volume of the water column; on the surface a uniform water layer with a temperature of $13^{\circ} \mathrm{C}$ and the thickness of approximately $8 \mathrm{~m}$ are created. (Figure 3d).

In summer, in all the water areas the near-surface quasihomogeneous layer to a depth of 2-3 $\mathrm{m}$ is formed with the highest seasonal mean temperature of $19-20^{\circ} \mathrm{C}$. At lower levels the temperature slightly drops, and everywhere there is a fairly uniform layer with the thickness of about $10 \mathrm{~m}$. The seasonal thermocline is at a depth of 15-30 m (Figure 3); at deeper levels, temperature continues to gradually decrease. From the depth of $35 \mathrm{~m}$ and to the bottom there is a quasihomogeneous layer with a temperature of $3-4^{\circ} \mathrm{C}$. 
The vertical convective processes that occur with the onset of autumn create a quasihomogeneous layer with the capacity of up to $30-40 \mathrm{~m}$ and temperature of about $13^{\circ} \mathrm{C}$ in the temperature distribution field in all the subregions.

It should be noted that near the Cape Taran, the temperature at the bottom in autumn is $6.5^{\circ} \mathrm{C}$ that is higher than in other seasons by $2.5^{\circ} \mathrm{C}$ (Figure 3a).

\section{Discussion}

A comparison of the vertical profiles of salinity by the instrumental measurement data and constructed by the climate data (World Ocean Atlas 2013) showed an overestimation of quantitative values for climate profiles. The vertical climate profiles of salinity for the shallowest area Coastal Zone do not match the calculated ones either morphologically or quantitatively.

The two-layer distribution structure of the salinity field with a small halocline at depths of 25-30 $\mathrm{m}$ in the areas of Sambia-Curonian hills and the North Coast presented in the World Ocean Atlas 2013 has never been confirmed by any in-situ measurements.

The climatic and calculated seasonal mean temperature profiles have very much in common. A good correlation of the overall structure of profiles with a slight difference in quantitative estimates is recorded for the North Coast region. In other regions, only the winter temperature distribution profiles are most similar.

The experimental data obtained make it possible to state that for the coastal water areas the penetration of warming and cooling reaches $30-35 \mathrm{~m}$. These values of the convection penetration depth are somewhat lower than those reported for the Gdansk Basin as a whole (Dubravin et al., 2012).

Due to small depths, and therefore a lower heat reserve of coastal waters of the Coastal Zone subregion there is a particular distribution of temperature fields. Each season here can be characterised by the creation of quasihomogeneous layers to the depths of wind and wave mixing manifestations with a thickness of 10-12 metres. The waters desalinated by the continental runoff in spring contributes to the formation of a layer with lower values of salinity in summer and autumn.

\section{Conclusion}

The performed analysis of the experimental data confirmed that the vertical thermohaline structure has many regional features in the Kaliningrad region's coastal waters. The vertical profiles of the seasonal temperature and salinity distribution calculated with the instrumentation data do not match the known climatic values.

The winter period can be characterised by the emergence of inverse thermal stratification and creation of a cold and thin near-surface layer with temperatures ranging from 0 to $2^{\circ} \mathrm{C}$ and capacity up to $4 \mathrm{~m}$. In the bottom area of the Coastal Zone an anomaly is observed in the salinity field.

Spring warming transforms the inverse thermal stratification of coastal waters into the direct one. On the entire water area an increase in temperatures can be recorded. The depth of the warm-up in various areas is 4-8 $\mathrm{m}$. In the salinity distribution field in the near-surface layer, desalination caused by the increase in the river and continental runoff occurs.

Summer warming creates a two-layer thermal stratification and water intermittency by salinity. Thermocline is at the depths of $15-30 \mathrm{~m}$. The top layer is typical of the maximum annual temperature values of $16-20^{\circ} \mathrm{C}$.

Autumn cooling and intense convection generate quasihomogeneous layers powerful in terms of thickness (30-36 m.). The temperatures in the bottom layer throughout the waters reach their maximum annual values.

\section{Acknowledgement}

This work was supported by the grants: Russian Foundation for Basic Research (RFFI) 15-35-51006 - mol_nr; 15-3550984 - mol_nr; 13-05-41374 - RGO_a.

\section{References}

Atlas 'The Climate of the Seas of Russia and Key Areas of the World Ocean' (2015) Unified State System of the World Ocean Status Information (ESIMO) [Online] Available: http://www.esimo.ru/atlas/Balt/1_1.html (March 27, 2015).

Atlas morza Bałtyckiego: opracowanie zespołowe (1994). A. Majewski i Zbygnew Lauer (eds.). Isntytut meteorologii i gospodarki wodnej. Warsawa.

Babakov, A.N. (2003). Spatial and Temporal Structure of Sediment Flows and Migration in the Baltic South-Eastern Coastal Zone 
(Sambian Peninsula and Curonian Spit): thesis. ... Ph.D. in Geography. Kaliningrad: Kaliningrad State University.

Belkin, I.M. (1991) Morphological and Statistical Analysis of the Ocean Stratification. L.: Gidrometeoizdat (Hydrometeo Publishers).

Dubravin, V. F., \& Stont, Zh. I.(2012) Hydrometeorological Mode, Water Structure and Circulation . In Oil and the Environment of the Kaliningrad Region (p. 69-105). Volume II: Sea. Kaliningrad: Terra Baltica,.

Leontiev, I.O. (2001) Coastal Dynamics: Waves, Currents, Sediment Flows. Moscow: GEOS.

Piterbarg, L.I., \& Gritsenko, V.A. (1983). Elimination of 'Emissions' in the Range of Hydrophysical Measurements through Median Filtering . Oceanology. Volume XXIII, No 1, 161-163.

Terziev, F.S., \& Rozhkov, V.A., \& Smirnova, A.I. (1992). Hydrometeorology and Hydrochemistry of the USSR Seas. Volume III. The Baltic Sea. Issue I. Hydrometeorological Conditions, under the editorship of. St. Petersburg. Gidrometeoizdat (Hydrometeo Publishers).

World Ocean Atlas 2013 Product Documentation (2015). National oceanographic data center of National Oceanic and Atmospheric Administration. [Online] Available: http://www.nodc.noaa.gov/OC5/indprod.html. (March 27, 2015). 